\title{
Influence of engine load on piston ring pack operation of an automotive IC engine
}

ARTICLE INFO

Received: 6 September 2021

Revised: 3 November 2021

Accepted: 20 December 2021

Available online: 14 February 2022
A piston-rings-cylinder (PRC) assembly determines the blowby, engine oil consumption, and friction and wear processes accompanying the system's operation. Thus, it is crucial for the whole IC engine efficiency and lifetime. A lot of research effort is put into increasing the performance of this complex and highly dynamic system. Advanced, comprehensive models play an important role in understanding and improving the PRC system.

In the presented work, the effect of load on the operation of the ring pack of an automotive gasoline engine is analyzed. A comprehensive model that covers the gas flow through the crevices of the PRC system, ring displacements in the groove, and ring lubrication was used for this analysis. The results of the simulations show that the local thickness of the oil film, especially near the piston top dead center is compared to the height of the combined surface roughness of a cylinder liner and piston rings, and friction-related asperity contact strongly increases as the engine load increases. The simulations also show that the engine load affects the axial displacements of the rings in the grooves but practically does not affect the thickness of the oil film left by the ring pack on the cylinder liner.

Key words: automotive IC engine, piston rings, blowby, ring dynamics, hydrodynamic lubrication, mixed friction

This is an open access article under the CC BY license (http://creativecommons.org/licenses/BY/4.0/)

\section{Introduction}

A piston-rings-cylinder (PRC) system is an important part of an internal combustion engine and strongly affects its efficiency and lifetime. The system decides about the combustion chamber airtightness, engine oil consumption, and friction and wear processes accompanying the operation of the system. Mechanical losses related to the friction in the system are usually the major contributor to the total mechanical losses of the engine $[5,6,8]$. Research to improve the system are crucial and widely conducted. Nowadays, the biggest effort in this field is focused on reducing friction losses while maintaining oil consumption and component life.

Because of the influences of many factors and the highly dynamic way of operation, the determination of the effect of a particular factor on the performance of the whole system is usually extremely difficult based only on empirical tests. Appropriate mathematical models help to evaluate the effects of both design and operational factors on the performance of the PRC system and thus improve system design $[4,9,14,17]$.

The engine oils of lower viscosity are used to reduce fluid friction. However, this makes the oil film thickness between the rings and the cylinder liner comparable to the surface roughness [1, 14, 21]. That means that not only fluid but also mixed lubrication should be taken into account while modelling the ring pack operation of a modern engine.

Numerical simulations of the operation of the gasoline engine ring pack with the use of the PRC system model considering mixed lubrication are presented. The results of simulations under the conditions of maximum engine power have been most often discussed in the literature. On the contrary, the results of calculations for partial engine loads, i.e., those in which car engines operate most often, are presented in this article.

\section{Modelling of piston ring pack operation}

\subsection{Developed sub-models}

The developed PRC system model consists of two main models: a) model of gas flow through the crevices existing between parts creating the system, and b) model of oil flow in the lubrication gap between the rings and cylinder liner. Furthermore, it consists of the following sub-models: model of contact of rough surfaces, model of axial movement of rings within piston grooves, and model of elastic torsional deformation of piston rings. All these models and submodels are coupled (Fig. 1).

The particular models and sub-models are briefly described below. All models and sub-models have been described in detail in previous publications [15-21].

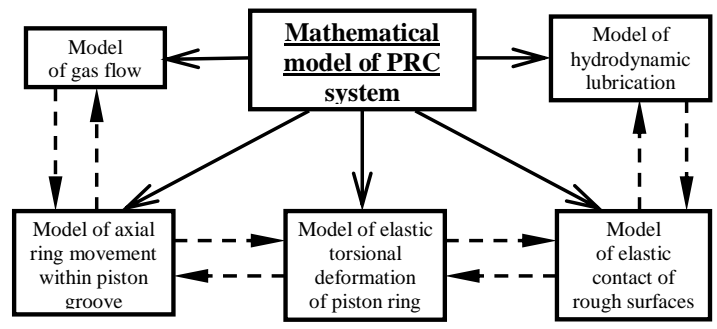

Fig. 1. A developed comprehensive model of the system: piston-ringscylinder (PRC) [21]

\subsection{Model of gas flow through the labyrinth seal of piston rings}

The gas flow model $[10,11,17]$ consists of several volume regions $\mathrm{V}_{1}, \mathrm{~V}_{2}, \ldots, \mathrm{V}_{5}$, which are connected by orifices with cross-section areas $A_{1}, A_{2}, \ldots, A_{6}$ (Fig. 2). The volumes $\mathrm{V}_{3}, \mathrm{~V}_{5}$, correspond to volumes between the piston rings, while volumes $V_{2}, V_{4}$ correspond to groove volumes behind rings. Orifices with cross-section areas $\mathrm{A}_{1}, \mathrm{~A}_{4}$ correspond to the ring end gaps, whereas orifices with cross-sections $A_{2}$, $\mathrm{A}_{3}, \mathrm{~A}_{5}, \mathrm{~A}_{6}$ correspond to ring-side crevices [10, 11]. 
It was also assumed that the gas flow through orifices is isentropic (depending on pressure ratio - subsonic or sonic). The heat transfer between gas in the particular regions and surrounding walls was taken into account.

Leaks between piston rings and cylinder liner were defined by flow areas of ring end gaps, which depend on the position of the piston in the cylinder.

In addition, the mathematical description takes into account changes in the volume of gas in the regions and cross-section areas between the rings and the piston grooves due to axial movement of the rings $[5,7,8,11,14]$.

In the mathematical model of these phenomena, equations of the following physical laws are utilized (here given for a gas volume region number $k$ ):
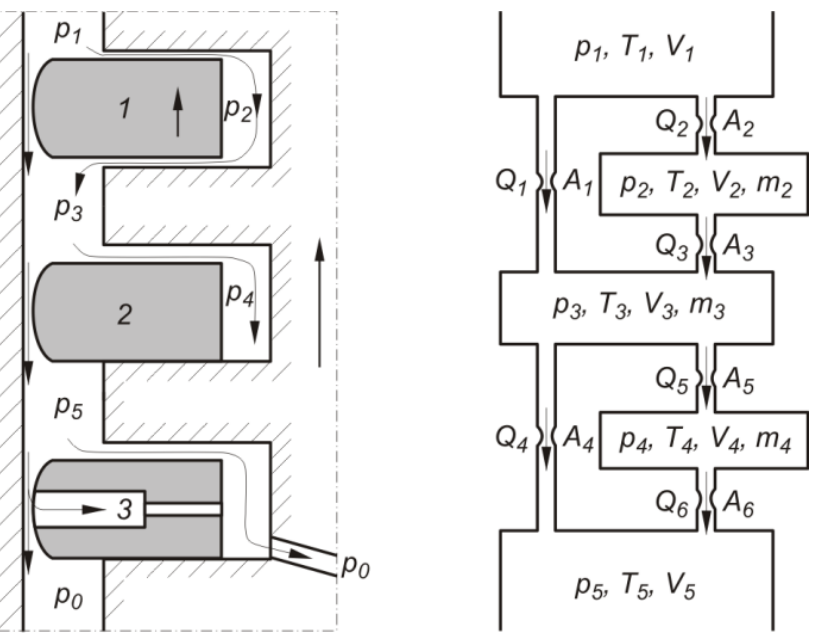

Fig. 2. Scheme of gas flow through the labyrinth seal: piston-ringscylinder system and applied physical model for the ring pack of three piston rings [21]

equation of mass balance:

$$
\mathrm{dm}_{\mathrm{k}}=\sum_{\mathrm{i}} \mathrm{dm}_{\mathrm{In}_{\mathrm{i}}}-\sum_{\mathrm{j}} \mathrm{dm}_{\mathrm{Out}_{\mathrm{j}}}
$$

equation of energy balance:

$$
\begin{gathered}
\sum_{\mathrm{i}} \mathrm{dm}_{\mathrm{In}_{\mathrm{i}}} \cdot \mathrm{h}_{\mathrm{In}_{\mathrm{i}}}-\sum_{\mathrm{j}} \mathrm{dm} \mathrm{m}_{\mathrm{Out}_{\mathrm{j}}} \cdot \mathrm{h}_{\mathrm{Out}_{\mathrm{j}}}-\delta \mathrm{Q}_{\text {Wall }}-\delta \mathrm{E}_{\mathrm{fri}}= \\
\mathrm{d}\left(\mathrm{m}_{\mathrm{k}} \cdot \mathrm{u}_{\mathrm{k}}\right)+\mathrm{p}_{\mathrm{k}} \cdot \mathrm{dV} \mathrm{V}_{\mathrm{k}}
\end{gathered}
$$

gas state equation in differential form:

$$
\mathrm{dT}_{\mathrm{k}}=\mathrm{T}_{\mathrm{k}} \cdot\left(\frac{\mathrm{dp}_{\mathrm{k}}}{\mathrm{p}_{\mathrm{k}}}+\frac{\mathrm{dV}_{\mathrm{k}}}{\mathrm{V}_{\mathrm{k}}}-\frac{\mathrm{dm}_{\mathrm{k}}}{\mathrm{m}_{\mathrm{k}}}\right)
$$

where: $\mathrm{m}$ - gas mass, $\mathrm{p}$ - gas pressure, $\mathrm{T}$ - gas temperature, $\mathrm{u}$ - internal gas energy, $\mathrm{h}$ - gas enthalpy, $\mathrm{Q}$ - heat transferred through cylinder walls, $\mathrm{E}$ - friction loss energy; Indexes: In - gas inflow, Out - gas outflow, i - number of inflow channel, $\mathrm{j}$ - outflow channel number, $\mathrm{k}$ - analysed gas volume.

The pressure variation over the top ring was determined by pressure measurements inside the cylinder during a cycle of its operation. The pressure between all the piston rings was calculated using the above-presented gas flow model. For this purpose, a computer program GASFLOW was developed and applied [15-21].

\subsection{Model of mixed lubrication}

Two main cases of oil flow in the PRC system are presented in Fig. 3.
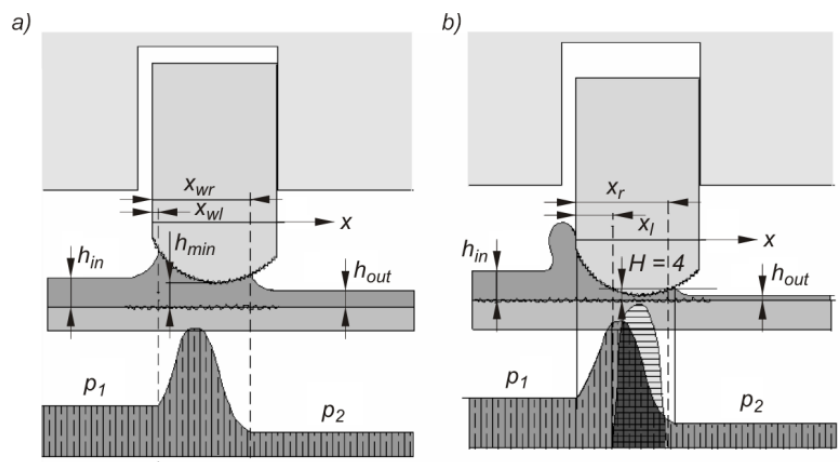

Fig. 3. Scheme of gap between the ring face and cylinder liner in the case of: a) fluid and b) mixed friction [21]

A one-dimensional form of the modified Reynolds equation developed by Patir and Cheng [12, 13] has been used to calculate hydrodynamic forces in the case of rough gap surfaces. This equation is applicable to any general roughness structure and takes the following form that contains sliding and squeeze motion:

$$
\frac{\partial}{\partial x}\left(\varphi_{x} \frac{h^{3}}{12 \mu} \frac{d \bar{p}}{d x}\right)=\frac{U}{2} \frac{d \bar{h}_{T}}{d x}+\frac{U}{2} \sigma \frac{d \varphi_{S}}{d x}+\frac{d \bar{h}_{T}}{d t}
$$

where: $\mathrm{t}$ - time; $\mathrm{x}$ - coordinate along with the cylinder liner; $\mathrm{h}$ - nominal oil film thickness; $\mathrm{h}_{\mathrm{T}}$ - the average gap between the ring and cylinder; $\mathrm{p}$ - hydrodynamic pressure; $\mathrm{U}-$ axial ring velocity; $\mu-$ dynamic oil viscosity; $\mathrm{v}=\partial \mathrm{h}_{\mathrm{T}} / \partial \mathrm{t}-$ radial ring velocity, $\sigma-$ composite root mean square roughness of sliding surfaces.

To preserve the solution of equation (4), it is necessary to describe the boundary conditions concerning oil flow. The upstream boundary condition states that the hydrodynamic pressure is equal to the gas pressure $\mathrm{p}_{1}$ (see Fig. 3a):

$$
\mathrm{p}\left(\mathrm{x}_{\mathrm{wl}}\right)=\mathrm{p}_{1}
$$

The downstream boundary condition states that the oil pressure is equal to the gas pressure $\boldsymbol{p}_{\mathbf{2}}$ and the pressure gradient is equal to zero, which corresponds to the so-called "Reynolds assumption":

$$
\mathrm{p}\left(\mathrm{x}_{\mathrm{wr}}\right)=\mathrm{p}_{2} \quad \text { and }\left.\quad \frac{\partial \mathrm{p}}{\partial \mathrm{x}}\right|_{\mathrm{X}_{\mathrm{wr}}}=0
$$

The hydrodynamic force (per unit circumference) $F_{h}$ $[\mathrm{N} / \mathrm{m}]$ can be calculated by integration of the hydrodynamic pressure distribution as follows:

$$
F_{h}=\int_{x_{w l}}^{x_{w r}} p(x) d x
$$

Then the hydrodynamic friction force $F_{\text {fri }}[N / m]$ can be obtained:

$$
F_{f r i}=\int_{x_{w l}}^{x_{w r}}\left(\frac{h}{2} \frac{\partial p}{\partial x}-\frac{\mu U}{h}\right) d x
$$

In addition, the power loss $\mathrm{P}_{\text {fri }}[\mathrm{W} / \mathrm{m}]$ can be calculated as follows:

$$
\mathrm{P}_{\text {fri }}=\left|\mathrm{F}_{\mathrm{fri}} \cdot \mathrm{U}\right|+\left|\mathrm{F}_{\mathrm{h}} \cdot \frac{\partial \mathrm{h}}{\partial \mathrm{t}}\right|
$$


The significance and mathematical description of empirical coefficients $\phi_{\mathrm{X}}, \phi_{\mathrm{S}}$ concerning the equation (4) are presented in works $[12,13]$.

The effects of interacting asperities of piston ring and cylinder liner surfaces were modelled using the mathematical model developed by Greenwood and Tripp [3], which was described in detail in publication [17].

The numerical solution of the Patir\&Cheng equation (4) is based on the implicit finite difference scheme. For this purpose, the computer program RINGAS has been developed and applied [15-21].

\subsection{Model of ring torsional deformation and ring axial movement in the piston groove}

A scheme of forces acting on a piston ring, action lines, and distances between these forces and the centre of gravity $\mathrm{S}$ of the ring cross-section are shown in Fig. 4. All the forces are referenced to the unit of the ring circumference $c_{i m c}$ (unit forces $[\mathrm{N} / \mathrm{m}]$ ).

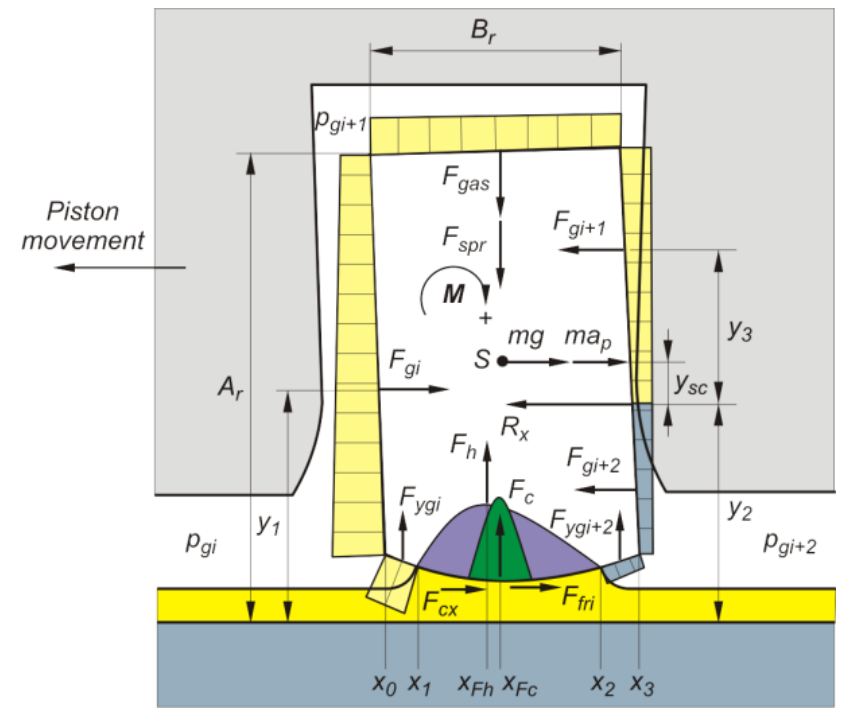

Fig. 4. Scheme and definitions of forces acting on a piston ring. Nomenclature: $F_{h}$ - hydrodynamic normal force, $F_{c}$ - contact normal force, $F_{s p r}$ ring spring force, $F_{\text {gas }}$ - back ring gas force, $F_{y g i}$ - leading edge gas force, $\mathrm{F}_{\mathrm{ygi+1}}$ - trailing edge gas force, $\mathrm{R}_{\mathrm{x}}$ - groove reaction force, $\mathrm{F}_{\text {fri }}$ - viscous friction force, $\mathrm{F}_{\mathrm{cx}}$ - contact friction force, $\mathrm{F}_{\mathrm{gi}}$ - leading side gas force, $\mathrm{F}_{\mathrm{gi}+1}$, $\mathrm{F}_{\mathrm{gi}+2}$ - trailing side gas forces, $\mathrm{m}$ - ring mass, $\mathrm{g}$ - gravitational acceleration, $a_{p}-$ piston acceleration [21]

A typical set of equations for the single lip piston ring has the following form (see Fig. 4):

a) in the radial direction

$$
\Sigma \mathrm{F}_{\mathrm{r}}=\mathrm{F}_{\mathrm{h}}+\mathrm{F}_{\mathrm{c}}+\mathrm{F}_{\mathrm{yg}_{\mathrm{i}}}+\mathrm{F}_{\mathrm{yg}_{\mathrm{i}+2}}-\mathrm{F}_{\mathrm{spr}}-\mathrm{F}_{\text {gas }}=0
$$

b) in the axial direction

$$
\begin{gathered}
\Sigma F_{\mathrm{x}}= \\
\mathrm{R}_{\mathrm{x}}-\mathrm{F}_{\text {fri }}-\mathrm{F}_{\mathrm{cx}}+\mathrm{F}_{\mathrm{g}_{\mathrm{i}+1}}+\mathrm{F}_{\mathrm{g}_{\mathrm{i}+2}}-\mathrm{F}_{\mathrm{g}_{\mathrm{i}}}-\frac{\mathrm{m}}{\mathrm{c}_{\mathrm{imc}}}\left(\mathrm{g}+\mathrm{a}_{\mathrm{p}}\right)=0
\end{gathered}
$$

Using these equations, the reaction force $R_{x}$ between the ring and piston groove in every time step can be calculated. If the sign of this force changes, the axial movement of the ring in the piston groove begins. At this point, the value of the reaction force $R_{x}=0$ and the axial movement of the ring relative to the piston groove can be described by the following differential equation: $\frac{m}{c_{i m c}} \frac{d^{2} x_{r}}{d t^{2}}=-F_{f r i}-F_{c x}+F_{g_{i+1}}+F_{g_{i+2}}-F_{g_{i}}-\frac{m g}{c_{i m c}}$

The ring movement $x_{\mathrm{r}}$ completes when the ring reaches the opposite side of the piston groove.

Similarly, like in articles of Dowson [2] and Tian et al. [14], the twist around the centre of gravity of the ring crosssection (point $\mathrm{S}$ in Fig. 4) can be described by the following equation of equilibrium of acting moments:

$$
\begin{gathered}
\Sigma M_{S}=F_{h}\left(x_{S}-x_{F_{h}}\right)+F_{c}\left(x_{S}-x_{F_{c}}\right)-\left(F_{f r i}+F_{c x}\right) \frac{A_{r}}{2} \\
-F_{g_{i}}\left(y_{2}+y_{s c}-y_{1}\right)- \\
F_{g_{i+1}}\left(y_{3}-y_{s c}\right)+F_{g_{i+2}}\left(\frac{y_{2}}{2}+y_{s c}\right)+R_{x} \cdot y_{s c}-K \cdot \theta=0
\end{gathered}
$$

Estimating the ring torsional stiffness $\mathrm{K}$ and using the equation (13) of moment equilibrium, the ring twist angle $\theta$ can be calculated. All the piston grooves are assumed to have curved surfaces in the radial direction (Fig. 4) due to their typical wear profiles. However this time, the effect of ring twist has not been taken into account.

\section{Experimental verification of developed models}

The model has been verified for a two-stroke marine Diesel engine [15-17]. The experimental verification of the model of gas flow through the labyrinth seal of piston rings was carried out using measurements of unsteady gas pressure: in the cylinder, between the piston rings, and under piston performed by piezoelectric sensors mounted in the piston. A satisfactory qualitative and quantitative compatibility of the analyzed pressure variations has been achieved. The maximal relative differences between measured and calculated pressures have not exceeded $15 \%[15,17]$.

On the other hand, the experimental verification of the hydrodynamic model of piston rings involved measurement of scraped oil volumes by a gland-box of a two-stroke marine engine. Examination of scraped oil volumes by the ring pack (of the gland-box of a marine IC engine) proves a satisfactory quantitative agreement between numerical and experimental results. The maximal relative differences between measured and calculated values have not exceeded $10 \%$ [15, 17]. Unfortunately, similar measurements for piston ring packs of tested engines have not been carried out.

\section{Computational results}

\subsection{Main data of the tested engine}

The simulations have been done for a four-stroke sparkignition engine of a middle-class passenger car operating at low, medium, and high load at a constant rotational speed of $2000 \mathrm{rpm}$. The main data of the engine is presented in Table 1.

Table 1. Engine specification

\begin{tabular}{|c|c|}
\hline Cylinder bore [mm] & 84 \\
\hline Piston stroke [mm] & 90 \\
\hline Number of cylinders & 4 \\
\hline
\end{tabular}

The type of ring set considered is common in car engines. It consists of three rings: a compression ring, a scraper ring, and a two-lip oil ring. The main dimensions of piston rings are presented in Table 2. All the rings have conventional straight ring end gaps. 
Table 2. Main parameters of piston rings

\begin{tabular}{|l|c|c|c|}
\hline \multicolumn{1}{|c|}{ Parameter } & Ring 1 & Ring 2 & Ring 3 \\
\hline Total axial width [mm] & 1.20 & 1.50 & 4.0 \\
\hline Axial width (upper land) [mm] & - & - & 1.0 \\
\hline Axial width (lower land) [mm] & - & - & 1.0 \\
\hline $\begin{array}{l}\text { Radius of parabolic sliding surface } \\
{[\mathrm{mm}]}\end{array}$ & 180 & 180 & 244 \\
\hline $\begin{array}{l}\text { Offset of parabolic sliding surface } \\
{[\mathrm{mm}]}\end{array}$ & 0.30 & 1.12 & 2.0 \\
\hline Radial thickness [mm] & 3.8 & 3.8 & 3.8 \\
\hline Nominal ring end gap [mm] & 0.20 & 0.30 & 0.30 \\
\hline Mass [g] & 12.5 & 16.7 & 25 \\
\hline $\begin{array}{l}\text { Elastic tension force (per unit of } \\
\text { circumference) [N/m] }\end{array}$ & 375 & 350 & 1545 \\
\hline
\end{tabular}

The surface geometry of the piston ring package, with vertical dimensions magnified by a factor of 1000 relative to the horizontal ones, is depicted in Fig. 5. All the rings are barrel-shaped.

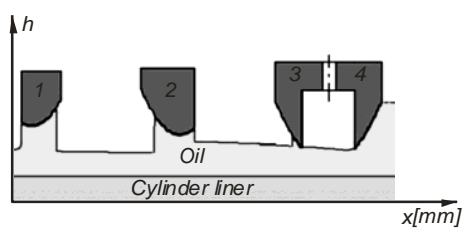

Fig. 5. Ring pack geometry under consideration (1- compression ring, 2 - scraper ring, 3 - the upper lip of the oil ring, and 4 - the lower lip of the oil ring)

The lubrication parameters of the PRC system can be seen in Table 3. The main parameters of the rough structure of the liner and ring surface are presented in Table 4.

Table 3. Lubrication parameters of the analyzed PRC system [19]

\begin{tabular}{|l|c|}
\hline Oil type & $\begin{array}{c}\text { Multigrade SAE } \\
10 \mathrm{~W} / 50\end{array}$ \\
\hline Oil density & $\rho=900 \mathrm{~kg} / \mathrm{m}^{3}$ \\
\hline $\begin{array}{l}\text { Growth velocity of the oil film thickness due to } \\
\text { oil fog condensation on the cylinder liner under } \\
\text { the ring pack }\end{array}$ & $\mathrm{v}_{\text {fog }}=800 \mu \mathrm{m} / \mathrm{s}$ \\
\hline $\begin{array}{l}\text { Decrease velocity of the oil film thickness in } \\
\text { the combustion chamber due to evaporation }\end{array}$ & $\mathrm{v}_{\text {evap }}=10 \mu \mathrm{m} / \mathrm{s}$ \\
\hline
\end{tabular}

Table 4. Surface roughness parameters [19]

\begin{tabular}{|l|c|c|}
\hline Surface data parameters & Cylinder liner & Piston rings \\
\hline RMS roughness & $\sigma_{1}=0.22 \mu \mathrm{m}$ & $\sigma_{2}=0.044 \mu \mathrm{m}$ \\
\hline Elastic modulus & $\mathrm{E}_{1}=1.13 \cdot 10^{11} \mathrm{~N} / \mathrm{m}^{2}$ & $\mathrm{E}_{2}=1.5 \cdot 10^{11} \mathrm{~N} / \mathrm{m}^{2}$ \\
\hline Poisson's ratio & $v_{\mathrm{P} 1}=0.26$ & $\nu_{\mathrm{P} 2}=0.25$ \\
\hline Combined parameters & \multicolumn{2}{|c|}{ Cylinder liner and piston rings } \\
\hline RMS roughness & \multicolumn{2}{|c|}{$\sigma=0.224 \mu \mathrm{m}$} \\
\hline Asperity density & \multicolumn{2}{|c|}{$\beta=1.114 \cdot 10^{12} \mathrm{~m}^{-2}$} \\
\hline $\begin{array}{l}\text { Asperity radius/ curva- } \\
\text { ture }\end{array}$ & \multicolumn{2}{|c|}{$\beta=0.2 \cdot \mu \mathrm{m}$} \\
\hline
\end{tabular}

\subsection{Calculation results}

During experimental measurements, the pressure variations in the first cylinder were measured for three engine loads, i.e., small (engine torque of $\mathrm{M}=10 \mathrm{Nm}$ ), medium $(100 \mathrm{Nm})$, and high $(140 \mathrm{Nm})$ at a constant rotational speed of $2000 \mathrm{rpm}$. The following maximum gas pressure values in the cylinder can be seen (Fig. 6): $1.66 \mathrm{MPa}$ at low load,
4.95 $\mathrm{MPa}$ at medium load, and 4.48 $\mathrm{MPa}$ at high load. Although the peak gas pressure in the cylinder at high load is lower than at medium load, the mean indicated pressures increase with the engine load (Table 5).

Table 5. Load parameters of an automotive engine under consideration at the rotational speed of $2000 \mathrm{rpm}$

\begin{tabular}{|c|c|c|c|}
\hline \multirow{2}{*}{ Engine load parameters } & \multicolumn{3}{|c|}{ Engine load (at 2000 rpm) } \\
\cline { 2 - 4 } & Low & Medium & High \\
\hline Engine torque M [Nm] & 10 & 100 & 140 \\
\hline Mean indicated pressure [MPa] & 0.150 & 0.703 & 0.954 \\
\hline
\end{tabular}

The pressure variation over the top ring was assumed to be equal to the pressure measured inside the cylinder during a cycle of its operation.

Typically, the figures that will follow show variations of some physical parameters as functions of the crankshaft rotation angle, beginning from the piston bottom dead centre (BDC) of the four-stroke engine operation $\left(0^{\circ}\right)$. In this case, the end of the compression phase is at $180^{\circ}$ of the crankshaft rotation (piston top dead centre - TDC).

The higher the gas pressure, the stronger the radial gas force acting to increase the ring diameter. It means that the radial gas force can be many times greater than the natural force due to ring stiffness acting in the same direction. First of all, the top ring is strongly pressed against the cylinder liner surface. For this reason, the comparisons of computational results concerning different engine loads are presented for the top piston ring (Fig. 7-9).

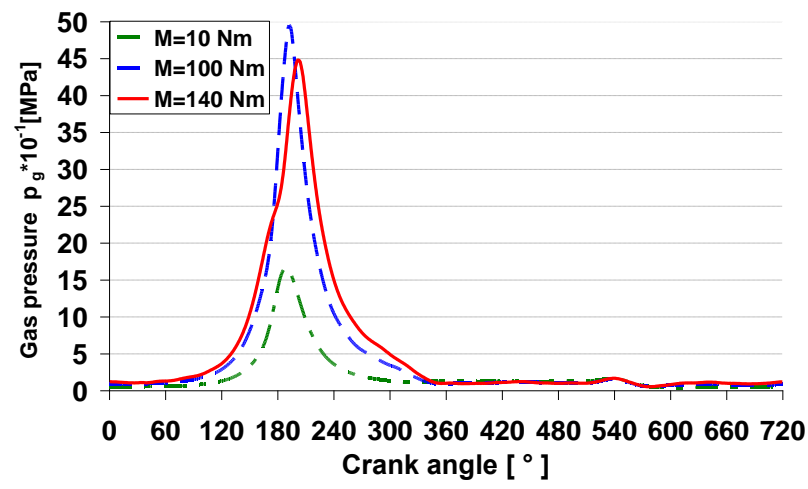

Fig. 6. Gas pressure variations in cylinder versus crank angle for low, medium, and high engine load operation at a rotational speed of $2000 \mathrm{rpm}$

In Fig. 7, axial lifts of the top ring in the piston groove as a function of crank angle for three analysed engine loads are shown. Due to significant changes in gas pressure the axial movements of the ring within its piston groove can be observed. This phenomenon takes place twice during the whole cycle $\left(0-720^{\circ}\right)$ of the four-stroke engine in case of the low load, i.e., in crank angle ranges $240-350^{\circ}$ and $556^{\circ}$ up to $128^{\circ}$ of the new engine operation cycle. Quick gas pressure variations in the crank angle range $258-351^{\circ}$ are followed by five oscillations of axial movement of the top ring in cases of medium and high loads. In addition, longer ring lifts take place: one in the crank angle range 495-720 at medium engine load and two in crank angle ranges 493 $545^{\circ}$ and $556-640^{\circ}$ at high engine load. 


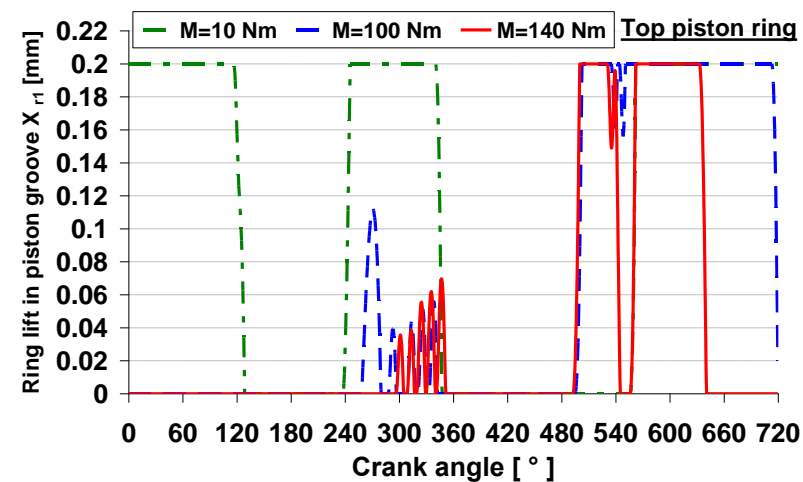

Fig. 7. Variations of the top ring lift $X_{\mathrm{r} 1}$ in the groove versus crank angle for three engine loads

The nominal axial clearance of the top ring in piston grooves equals $0.20 \mathrm{~mm}$ and for the second and third piston ring $-0.30 \mathrm{~mm}$. Each short-lasting ring movement in the piston groove is followed by a change of the acting point of the reaction force $R_{x}$ to the other flank of the piston groove and also a sign change of this force (Fig. 4). Obviously, $R_{x}$ $=0$ during the ring movement between the two piston groove flanks.

The total radial force acting on a piston ring compensates the gas force $F_{\text {gas }}$, hydrodynamic force $F_{h}$, elastic contact force due to surface roughness $F_{c}$, and spring force $\mathrm{F}_{\mathrm{spr}}$ (see Fig. 4 and equation (5)). In Fig. 8, variations of total radial forces of the top piston ring for different engine loads versus crank angle are presented.

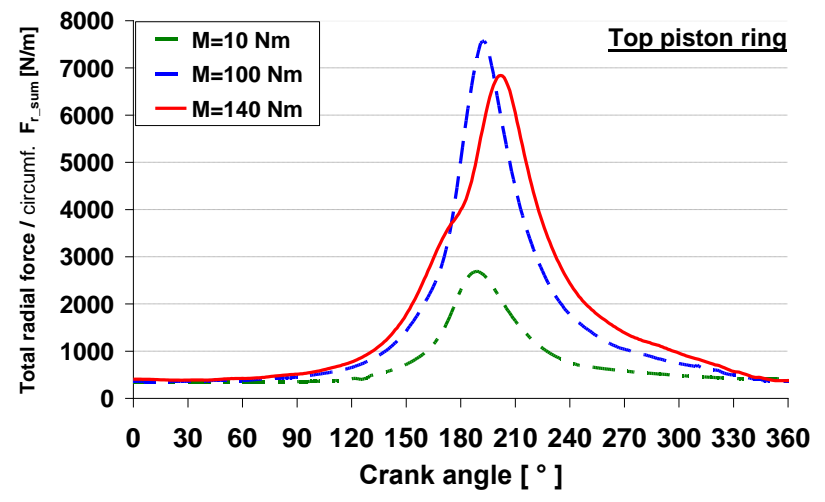

Fig. 8. Variation of total radial unit force (hydrodynamic and elastic contact) $F_{r}$ for the top piston ring versus crank angle

Variations of the total radial force look similar to the variations of gas pressures in the cylinder (Fig. 6). The top piston ring's maximum radial forces (per unit of piston ring circumference) can be seen: $2680 \mathrm{~N} / \mathrm{m}$ at low load, 7570 $\mathrm{N} / \mathrm{m}$ at medium load, and $6830 \mathrm{~N} / \mathrm{m}$ at high load.

The total friction forces acting on piston rings consist of two tangential components: hydrodynamic and elastic contact forces due to surface roughness. Variations of total friction forces for the top ring as functions of crank angle are presented in Fig. 9.

Maximum values of hydrodynamic components of friction forces are much lower than components of elastic contact forces - at high engine load, these components are equal to $17 \mathrm{~N} / \mathrm{m}$ ) and $425 \mathrm{~N} / \mathrm{m}$, correspondingly. The mixed friction forces are particularly noticed near the top dead centre (at the beginning of the expansion phase), where the highest gas pressure and oil temperature are reached. The sign change of these forces at TDC results from the change in the direction of piston movement. The higher engine load, the bigger value of total friction force acting on the sliding surface of the top ring can be observed. The following maximum total friction forces (per unit of piston ring circumference) of the top ring can be seen: $111 \mathrm{~N} / \mathrm{m}$ at low load, $246 \mathrm{~N} / \mathrm{m}$ at medium load, and $440 \mathrm{~N} / \mathrm{m}$ at high load.

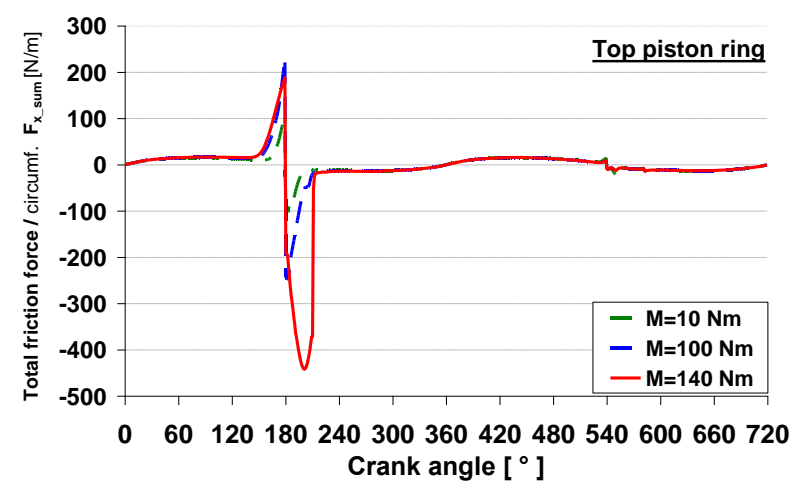

Fig. 9. Variation of total friction unit force $F_{x}$ for the top piston ring versus crank angle

Maximum values of hydrodynamic components of friction forces are much lower than components of elastic contact forces - at high engine load, these components are equal to $17 \mathrm{~N} / \mathrm{m}$ ) and $425 \mathrm{~N} / \mathrm{m}$, correspondingly. The mixed friction forces are particularly noticed near the top dead centre (at the beginning of the expansion phase), where the highest gas pressure and oil temperature are reached. The sign change of these forces at TDC results from the change in the direction of piston movement. The higher engine load, the bigger value of total friction force acting on the sliding surface of the top ring can be observed. The following maximum total friction forces (per unit of piston ring circumference) of the top ring can be seen: $111 \mathrm{~N} / \mathrm{m}$ at low load, $246 \mathrm{~N} / \mathrm{m}$ at medium load, and $440 \mathrm{~N} / \mathrm{m}$ at high load.

The total power losses related to the top ring motion versus crank angle are presented in Fig 10. These power losses significantly depend on instantaneous piston velocity. For this reason, their highest values of $90 \mathrm{~W}$ are mostly noticed at crank angles of $90^{\circ}, 270^{\circ}, 450^{\circ}$ and $630^{\circ}$, where the maximum piston velocity is reached, and they drop almost to zero at piston reverse points. Although the piston velocity is equal to zero at the reverse points, the total power loss can be different from zero because of the ring squeezing velocity $\partial \mathrm{h} / \partial \mathrm{t}$ (see Eq. (8)). The total power losses significantly depend on the engine load (Fig. 10). This is primarily due to asperity contact - hydrodynamic friction only slightly depends on the engine load, while the elastic contact forces due to surface roughness depend very strongly, primarily at the beginning of the expansion stroke.

In Fig. 11 the variations of the minimum oil film thickness in the gap of the top piston ring versus crank angle for three chosen engine loads are shown. It should be explained that hydrodynamic forces generated in the gap between liner and ring lip are proportional to the ring axial velocity. 


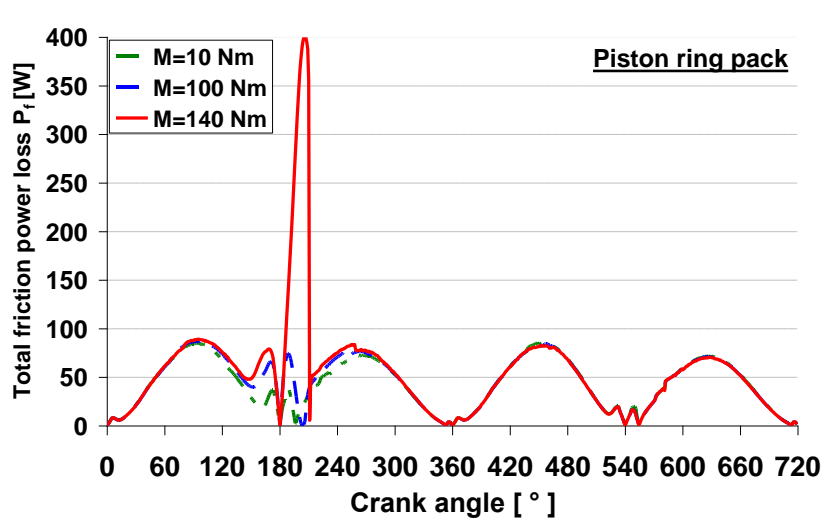

Fig. 10. Variations of total friction power loss $\mathrm{P}_{\mathrm{f}}$ versus crank angle

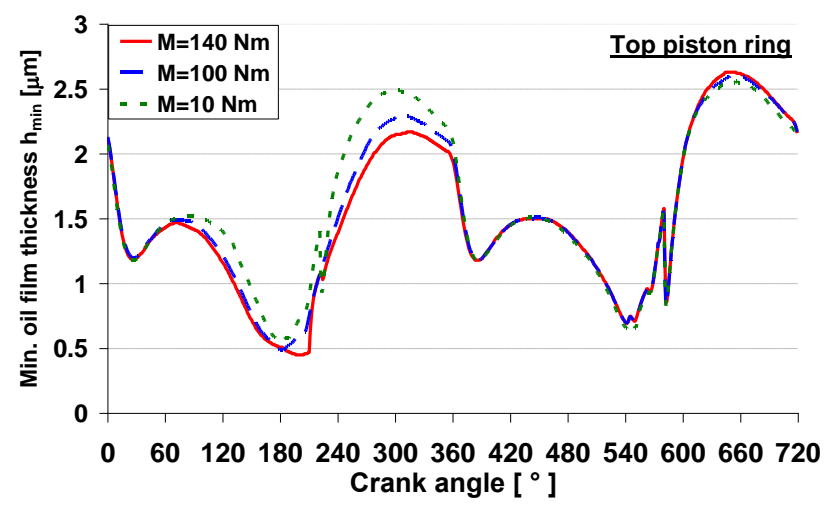

Fig. 11. Variations of the minimum oil film thickess in the gap of the top piston ring versus crank angle for three engine loads

During a cycle, the axial velocity tends to zero near the turning points (TDC and BDC). In these areas, the oil film thickness is strongly reduced, because the only force acting against the gas and ring stiffness forces is the hydrodynamic force generated by the squeeze velocity.

The higher engine load, the lower oil film thickness of the top ring can be observed, especially in compression and expansion strokes. In other two strokes a negligible influence of the engine load on the minimum oil film thickness is noticed.

The motion of the ring pack scrapes and distributes the oil on the cylinder liner leaving the oil film profiles shown in Fig. 12. An uneven oil film distribution along the cylinder liner can be clearly seen.

Low film thickness near the piston top dead centre (TDC) and peaks of accumulated oil near the leading ring lips should be noticed. The minimum oil film thickness at TDC is about $0.35 \mu \mathrm{m}$ and can be compared with the RMS roughness of the cylinder liner that equals $0.22 \mu \mathrm{m}$. The very low local values of oil film thickness near TDC can be explained by the high pressure of gas and high temperature in this area during the compression and working phases of engine operation. Due to high gas forces, piston rings are strongly pressed against the cylinder surface. On the other hand, the high temperature reduces the oil viscosity. The calculation results presented in Fig. 12 show a negligible influence of the engine load on the distribution of the oil film thickness on the cylinder surface.

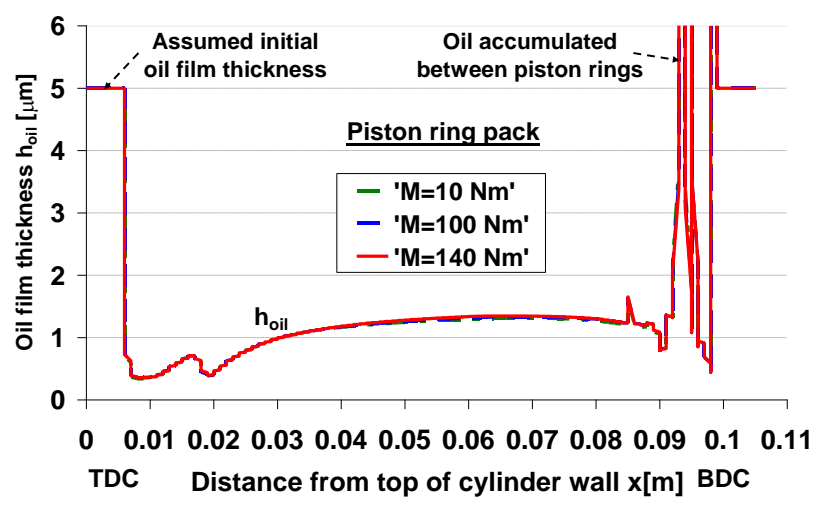

Fig. 11. Variations of the oil film thickness $\mathrm{h}_{\mathrm{oil}}$ left by the ring pack along cylinder wall

All the computational results of the PRC system have been carefully analyzed using a developed computer animation program called ANIMATE [15-21].

\section{Conclusions}

The major conclusions that may be drawn from the results are as follows:

1. The developed mathematical model and simulation program gives a lot of practical information that would be more complicated and expensive to obtain using experimental methods.

2. In order to use the simulation program, a number of essential input data are needed. They include dimensions of PRC system and pressure in the combustion chamber.

3. Simulations for automotive SI engine showed that:

- engine load affects the axial movements of the rings in the grooves,

- engine load strongly affects the elastic contact of the ring and cylinder surface asperities, and so the total power losses due to the ring friction,

- engine load practically does not affect the thickness of the oil film left by the ring pack on the cylinder liner.

\section{Acknowledgments}

The first author expresses his gratitude to Wärtsilä's $R \& D$ engine centre (nowadays: Winterthur Gas \& Diesel $L t d$.) in Winterthur (Switzerland) for having the opportunity to work on projects concerning mathematical modelling and numerical simulation of tribological systems of piston rings during several research periods at this company.

\section{Nomenclature}

PRC piston-ring-cylinder

TDC top dead center

BDC bottom dead center

RMS root mean square 


\section{Bibliography}

[1] BOLANDER, N.W., STEENWYK, B.D., SADEGHI, F. et al. Lubrication regime transitions at the piston ring - cylinder liner interface. Proceedings of the Institution of Mechanical Engineers, Part J: Journal of Engineering Tribology. 2005, 219, 19-31. https://doi.org/10.1243/135065005X9664

[2] DOWSON, D. Piston assemblies: background and lubrication analysis. Engine Tribology. Elsevier, Amsterdam 1993. https://doi.org/10.1016/S0167-8922(08)70013-0

[3] GREENWOOD, J., TRIPP, J.H. The contact of two nominally flat rough surfaces. Proceedings of the Institution of Mechanical Engineers. 1971, 185, 625-633. https://doi.org/10.1243/PIME_PROC_1970_185_069_02

[4] GULWADI, S.D. Analysis of tribological performance of a piston ring pack. Tribology Transactions. 2000, 43(2), 151162. https://doi.org/10.1080/10402000008982325

[5] HEYWOOD, J.B. Internal combustion engine fundamentals. McGraw-Hill Inc. 1988

[6] HOLMBERG, K., ERDEMIR, A. The impact of tribology on energy use and $\mathrm{CO}_{2}$ emission globally and in combustion engine and electric cars. Tribology International. 2019, 135, 389-396. https://doi.org/10.1016/j.triboint.2019.03.024

[7] KNOLL, G., PEEKEN, H., LECHTAPE-GRÜTER, R. et al. Computer-aided simulation of piston and piston ring dynamics. Journal of Engineering for Gas Turbines and Power. 1996, 118, 880-886. https://doi.org/10.1115/1.2817009

[8] KOSZAŁKA, G., HUNICZ, J. Comparative study of energy losses related to the ring pack operation in homogeneous charge compression ignition and spark ignition combustion. Energy. 2021, 235, 121388.

https://doi.org/10.1016/j.energy.2021.121388

[9] KOSZAŁKA, G., NIEWCZAS, A., GUZIK, M. Predicted and actual effect of cylinder liner wear on the blowby in a truck diesel engine. SAE Technical Paper 2008-01-1717. 2008. https://doi.org/10.4271/2008-01-1717

[10] KOSZAŁKA, G. Application of the piston-rings-cylinder kit model in the evaluation of operational changes in blowby flow rate. Eksploatacja i Niezawodność - Maintenance and Reliability. 2010, 4, 72-81.

[11] KOSZAŁKA, G., GUZIK, M. Mathematical model of piston ring sealing in combustion engine. Polish Maritime Research. 2014, 4(84), 66-78.

https://doi.org/10.2478/pomr-2014-0043
[12] PATIR, N., CHENG, H.S. An average flow model for determining effects of three-dimensional roughness on partial hydrodynamic lubrication. Journal of Tribology. 1978, 100(1), 12-17. https://doi.org/10.1115/1.3453103

[13] PATIR, N., CHENG, H.S. Application of average flow model to lubrication between rough sliding surfaces. Journal of Tribology. 1979, 101(2), 220-229. https://doi.org/10.1115/1.3453329

[14] TIAN, T. Dynamic behaviors of piston rings and their practical impact-part ii: oil transport, friction, and wear of ring/liner interface and the effects of piston and ring dynamics. Proceedings of the Institution of Mechanical Engineers, Part J: Journal of Engineering Tribology. 2002, 216, 229-247. https://doi.org/10.1243/135065002760199970

[15] WOLFF, A. Experimental verification of the model of piston ring pack operation of an internal combustion engine. The Archive of Mechanical Engineering. 2009, 56(1), 73-90. https://doi.org/10.24425/ame.2009.132089

[16] WOLFF, A. Influence of engine load on piston ring pack operation of a marine two-stroke engine. Journal of KONES Powertrain and Transport. 2012, 19(2), 557-569. https://doi.org/10.5604/12314005.1138276

[17] WOLFF, A. Simulation based study of the system pistonring-cylinder of a marine two-stroke engine. Tribology Transactions. 2014, 57(4), 653-667. https://doi.org/10.1080/10402004.2014.895886

[18] WOLFF, A. Influence of sliding surface roughness and oil temperature on piston ring pack operation of an automotive IC engine. IOP Conference Series: Materials Science and Engineering. 2016, 148, 1-10. https://doi.org/10.1088/1757-899X/148/1/012090

[19] WOLFF, A. Numerical analysis of gas flow through the labyrinth seal of piston rings of an automotive IC engine. IOP Conference Series: Materials Science and Engineering. 2018, 421, 1-11. https://doi.org/10.1088/1757899X/421/4/042082

[20] WOLFF, A. Influence of piston ring profiles and oil temperature distribution on cylinder liner lubrication of a marine two-stroke engine. Combustion Engines. 2019, 178(3), 257-263. https://doi.org/10.19206/CE-2019-345

[21] WOLFF, A. Numerical analysis of the system piston-ringcylinder of an automotive IC engine. SAE Technical Paper 2020-01-2160, 2020. https://doi.org/10.4271/2020-01-2160

Prof. Grzegorz Koszałka, DSc., DEng. - Faculty of Mechanical Engineering, Lublin University of Technology.

e-mail: g.koszalka@pollub.pl

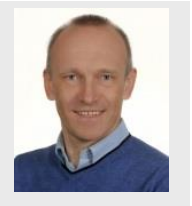

